\title{
浅谈初中化学教学中学生核心素养的培育
}

玛依努尔・托列哈孜

新疆省阿勒泰地区阿勒泰市第一中学

DOI:10.32629/er.v3i5.2718

[摘 要] 在传统教学工作的开展过程中, 大部分教师的工作重点都放在了学生学习成绩的提升问题上,并没有正确认识到学生其他素质提升的 重要性。特别是在当前教育体制改革和发展背景下, 素质教育模式对教育工作的影响更为显著, 其开展的主要目的就是对学生核心素养的培养和 发展, 避免出现学生学习模式的单一,引导学生和社会、生活进行紧密结合, 帮助学生实现健康和全面发展。为此, 本文就将对初中化学教学中学 生核心素养的培育问题展开详细研究, 希望对学生健全发展提供有效帮助。

[关键词] 初中化学; 核心素养; 培养

化学是中学教育中不可忽视的重要组成环节, 现阶段初中化学教学的 核心就是对学生核心素养的培养和提升。作为一项近几年提出的全新理论, 虽然这一理念具备较强的理论支撑, 但是在化学教育阶段仍然处于尝试和 起步发展阶段。所以, 怎样在教学工作中有效融合核心素养问题也是当前 教学工作者最需要关注和研究的重点问题。基于此, 本文就将对初中化学 教学中的核心素养培育问题进行研究。

\section{1 初中化学核心素养的内涵}

初中化学的核心素养指的主要就是化学学科在教学中实现学生个人 素养的提升, 学生在不断的学习和发展过程中, 可以借助化学思维进行问 题的解决。初中化学教育开展的过程中, 正处于学生刚刚接触化学知识初 级阶段, 按照教材要求, 学生在学习过程中可以获取到很多核心素养, 比如 在变化守恒的学习过程中梳理全新变化观, 在实验探究过程中可以将创新 知识全面应用到实验研究方法中, 这些素养对于学生树立健全的化学价值 观将起到十分重要的帮助 ${ }^{[1]}$ 。

\section{2 初中化学中对学生核心素养进行培育的对策}

2.1引导学生加强对化学基本知识的掌握

对学生学科知识学掌握能力的培养对于学生核心素养发展有着重 要帮助, 学生只有实现了对基本知识的有效学习, 才能更为全面的掌握 这门学科, 从而实现其他素质和能力的提升, 这也是广大教师需要在教 学工作中不断探索和研究的目标。受到应试教育的限制和影响, 教师在 教学工作中只是将知识传递给学生, 并将重点放在了考核内容的关注上, 此种方式虽然能帮助学生有效应对各种考试, 但是并不能帮助学生实现 基本知识辨识能力的提升, 对于学生自我学习能力的会起到一定限制和 影响 ${ }^{[2]}$ 。

初中阶段学生刚刚接触化学知识, 因此学生对于化学知识的掌握十分 有限, 在教学过程中, 很多教师为了节约时间对于一些不是重点的内容都 粗略讲解, 并没有对学生专门讲解相关的含义, 并且长时间的传统教育理 念使得大部分学生对教师的依赖性较强, 学生很难主动进行资料的查询, 对于一些化学术语的讲解只能片面理解, 因此在实际应用的过程中很可能 出现差错。比如很多学生不理解化学式和分子式的含义, 在使用的过程中 经常出现偏差。在学生看来, 分子式和化学相同, 所以也会将 $\mathrm{H} 20 、 \mathrm{NaCl} 1$ 错 误的理解为分子式, 但其实这些物质属于离子化合物, 并且存在形式为离 子晶体, 只能称之为化学式。在此种情况下, 教师在教学过程中就可以以课 外作业的方式引导学生对其定义进行查询和掌握 ${ }^{[3]}$ 。

在化学课程中涉及到的基本知识非常广泛, 教师并不能保证全部对学 生进行讲解, 因此对于一些较为基础或是相对简单的化学知识就需要教师 正确发挥引导作用, 从而引导和培养学生的主观能动性, 只有这样才能帮
助学生实现基本知识掌握能力的全面提升。

2.2 对学生科学研究能力进行培养

化学学科在教学过程中会涉及很多实验, 这些实验和化学概念、知识 存在十分密切的联系, 广大科学家也是在实验的帮助下对物质进行分析, 最终掌握化学物质的不同性质。所以实验课程的设置对于学生理解和掌握 化学知识也具备十分重要的影响和作用 ${ }^{[4]}$ 。一直以来, 我国教学过程中对 实验课程的重视程度都十分有限, 这一问题的出现使得学生的科学实验能 力难以的带有效提升, 甚至直接影响了国家科研水平的提升。基于此, 教师 更需要加强对传统教学方法的优化和调整, 充分提升对试验课程的重视程 度, 在对学生科学探究能力进行提升的过程中, 将试验课程转变为理论课 程教学的重要依据。

比如在初中化学氧气制取的实验中, 为了帮助学生更有效的掌握实 验材料, 培养学生对实验常用仪器掌握能力的提升, 教师在实验前可以 适当减少相应的实验材料, 学生在进入实验室后, 教师可以让学生进行 实验材料和仪器设备的检查, 之后引导学生在实验室的物品架上自行进 行材料核查。基于初中学生操作的实验项目比较少, 所以教师在教学工 作开展前需要对学生详细介绍实验步骤, 比如气密性的检查方式。在实 验开展过程中, 教师要尽可能减少对学生实验的干预, 而是将主动权交 给学生, 让学生主动进行操作。但是实验工作的开展要切实保证安全性 得到提升, 教师在学生实验过程中需要充分发挥监督作用, 如果学生出 现危险性行为一定要第一时间进行更正, 对其进行正确引导 ${ }^{[5]}$ 。在此种开 放性实验的教育过程中, 不仅能提升学生在课堂上动手操作的时间, 同 时学生的参与兴趣也将大大提升, 对于学生化学知识学习兴趣的提升有 着重要帮助。

2. 3对学生化学思维和实践能力的培养与优化

在化学课程开展过程中, 学生不仅要进行大量的知识的学习和记忆, 还需要加强对化学思维的培养, 从而在知识学习中合理应用化学思维。传 统教学方式中学生化学成绩得不到提升的重要原因就是因为学生在学习 过程中没能正确构建起思维方式, 所以对学习到的化学知识只能停留在记 忆阶段, 如果转变题型, 学生很难对其进行有效解决。而化学思维的构建和 实践能力之间本身就存在密切联系, 只有学生掌握了熟练的思维方式, 才 能在实践过程中对其进行有效应用 ${ }^{[6]}$ 。

实践能力的提升不仅需要教师对学生的化学思维进行正确培养和引 导, 还需要教师有针对性的帮助学生实现知识和生活的连接, 引导和帮助 学生认识到化学知识在生活中产生的重要影响。比如在对 “燃烧和灭火” 课题进行研究的过程中, 教师可以让学生查询生活中常见的灭火方式, 并 且让学生对灭火方式不当引发严重的问题进行研究。此种教学方式不仅能 


\section{幼儿亲社会行为产生动机的研究一一《合作才能赢》为例}

周欣

淮北师范大学

DOI:10.32629/er.v3i5.2739

[摘 要] 随着社会的不断发展, 亲社会行为已逐渐成为个体社会化的一个重要组成部分, 它有助于建立融洽的人际关系。当前国家一些指导文 件中对于3-6岁儿童亲社会行为进行了一些相关规定, 主要包括团结、合作、助人为乐及社会公德等亲社会行为。本文着重以亲社会行为中的 合作行为为着眼点, 并且从动机理论视角下出发, 采用文献分析的研究方法, 通过对大班《合作才能赢》案例的观察分析, 从多个角度归纳幼儿亲 社会行为产生的动机。

[关键词] 动机理论; 亲社会行为; 合作

\section{1 从活动实例中分析幼儿合作行为产生的外部动机}

由相关参考文献可以看出外部动机主要来自于外部环境的激发。那么 由笔者进行观察记录可以发现, 外部环境的激发也是促使儿童做出亲社会 行为的重要原因。一方面, 儿童从幼年开始, 就会看成年人的脸色行事, 就 会顺从成年人的指令来进行亲社会行为, 这便可以说是顺从权威; 另一方 面, 伴随着儿童身心年龄的逐步成长, 他们的认知能力和视野也会更加的 开阔, 他们也逐渐会考虑到自己行为的最终后果。因此我们可以从以下的 三个方面来叙述儿童亲社会行为的外部动机产生的原因。

1. 1幼儿合作行为产生的外部动机一一顺从权威

情景一:

观看视频《蚂蚁的合作》, 初步理解合作的意义。

提问: 你们看到了什么? 一只蚂蚁的本领大还是一群蚂蚁的本领大?

小结: 一只蚂蚁不能完成的事情, 许多只蚂蚁齐心协力, 共同努力, 通 过合作获得成功。

分析:

教师通过引入视频《蚂蚁的合作》让幼儿进行观看, 无形之中就已安 排好了整堂课的教学进程, 孩子们是跟着老师的节奏进行学习。教师出于 对儿童指导和教育的目的, 时常对儿童提出适合他们的行为以及发出他们 该如何正确做的要求, 如: 你们看见了什么? 一只蚂蚁的本领大还是一群 蚂蚁的本领大? 通过调查发现, 儿童在与成人互动的过程中呈现是顺从的 特点, 当教师或家长提出一个指令时, 例如一起完成一项有难度的任务, 儿 童往往会屈服于权威而顺从这项指令。有些儿童会因为想要得到奖赏或者 避免与惩罚而听从于家长或教师的指令。

1. 2 幼儿合作行为产生的外部动机一一互惠期待

对学生的知识面进行扩展, 还有助于学生对易燃、助燃材料性质的认知, 提升了学生的安全意识, 这对于学生化学思维和实践能力的提升都有着十 分显著的积极影响。

\section{3 结束语}

综上所述, 所谓学生核心素养培养就是对学生学习思维、逻辑能力的 提升。在中学教育阶段, 化学学科的重要性已经受到了教学工作者的广泛 关注, 所以在化学学科中对学生思维方式和解决问题能力进行提升尤为重 要。这也要求广大教学工作者要按照初中化学教育目标, 针对性的制定教 学方案, 从而在完善的教学方案引导下构建合理的教学目标, 在教学工作 中对学生进行化学知识的有效引导, 在提升学生化学知识掌握水平的基础 上, 引导学生实现核心素养水平的提升。

[参考文献]
情境二:

观看完了《蚂蚁的合作》视频, 教师进行提问和总结, 一只蚂蚁不能完 成的事情, 许多只蚂蚁齐心协力, 通过合作获得成功。然后联系生活讨论: 生活中你和谁合作过? 完成了什么事情? 接着引入下一环节, 游戏 “保护 报纸”, 尝试共同探索、协商、分工, 提高与同伴合作的能力。

两人尝试游戏, 探索合作的方法。

游戏材料: 将报纸中间撕出两个洞。

游戏规则: 一组幼儿尝试, 两名幼儿分别将头套进洞里, 音乐开始, 成 员分别把头套在洞里, 共同走到终点, 报纸没有断开的为合作成功。

讨论：合作的过程中怎样让报纸不断开?有什么方法?

小结: 他们手拉手, 方向相同, 速度相同, 距离近, 走的慢。采用两人合 作的方式进行第一次合作, 其他幼儿通过观察, 寻找合作成功的方法。游戏 结束后, 通过讨论、商量, 初步寻找合作成功的方法。

分析:

在《合作才能赢》这个案例 “保护报纸” 的游戏中, 怎样才能让有两 个洞的报纸不断开, 并且玩家能够伴随着音乐共同走到终点, 只有通过互 惠期待。互惠期待是互惠行为的另外一种表现模式, 是指双方拥有共同的 目标, 然后彼此之间相互帮助, 相互携手, 最终实现共同目标。

1. 3幼儿合作行为产生的外部动机一一声誉

情境三:

在《合作才能赢》这个案例中, 无论是第一次 “保护报纸” 的游戏, 还是第二次、第三次的集体游戏, 因为所有的小朋友都参加了这次的游戏 还有老师们在一旁观看, 无形之中对幼儿来说就有一种想要取得胜利的荣 誉感, 希望能够得到老师以及在场观众的表扬, 这对他们来说就是推动他

[1]蒙志科.初中化学教学中学生核心素养的培育对策分析 [J].新课 程 - 中学,2019,17(12):233.

[2]杨定国.浅谈初中化学教学中学生核心素养的培育[J]. 考试周 刊,2019,35(51):152-153.

[3] 李伯玲. 浅谈初中化学教学中学生核心素养的培育 [J]. 神 州,2019,26(5):108.

[4]李付.浅谈初中化学教学中学生核心素养的培育[J].新教育时代电 子杂志(学生版),2018,14(10):153.

[5]袁德力.刍议初中化学教学中学生核心素养的培育策略[J]. 读与写 (教师),2018,20(003):145.

[6]沈翔.浅谈初中化学教学中学生核心素养的培育[J].中学教学参 考,2016,11(29):94-95. 